\title{
Improving the water productivity of paddy rice (Oryza sativa L.) cultivation through water saving irrigation treatments
}

\author{
Joko Sujono $^{1^{*}}$, Naoki Matsuo ${ }^{2}$, Kazuaki Hiramatsu $^{3}$, Toshihiro Mochizuki $^{3}$ \\ ${ }^{1}$ Department of Civil and Environmental Engineering, Faculty of Engineering, Gadjah Mada University, Yogyakarta, Indonesia; \\ *Corresponding Author: jsujono@ugm.ac.id \\ ${ }^{2}$ Lowland Crop Rotation Research Team, National Agricultural Research Center for Kyushu Okinawa Region, Chikugo, Japan; \\ ${ }^{3}$ Department of Agro-Environmetal Sciences, Faculty of Agriculture, Kyushu University, Fukuoka, Japan.
}

Received 11 August 2011; revised 10 October 2011; accepted 27 October 2011.

\begin{abstract}
Rice grows well under certain condition and environment including soil, water and nutrients. Some researches have shown that traditional method with continues flooding need tremendeous amount of water for rice cultivation and gives low water productivity. To increase the water productivity, number of water saving irigation techniques have been studied and applied. Study on effect of number of water irrigation treatments on water productivity of rice was carried out. Eight irrigation treatments were conducted for growing rice in pot experiment i.e. shallow intermittent irrigation (SII), alternate wetting and drying (AWD1, AWD2, AWD3 and AWD4), shallow water depth with wetting and drying (SWD1 and SWD2), and semi-dry cultivation (SDC). The performance of those treatments in terms of agronomic and water parameters was compared to the shallow intermittent irrigation as a control method. The study reveals that the shallow intermittent irrigation needs the highest amount of water compare with other treatments. The lowest amount of water was achieved under the semi-dry cultivation. It could save water up to $18.4 \%$ compare to the control treatment. By using the alternate wetting and drying and the shallow water depth with wetting and drying treatments, irrigated water can be reduced up to $13.1 \%$ and $5.4 \%$, respectively. The highest grain was obtained by alternate wetting and drying (AWD4) and the semi-dry cultivation yielded the smalest grain. On average the alternate wetting and drying and shallow water depth with wetting and drying increased the grain yield by $22.9 \%$ and $17.9 \%$, whereas the
\end{abstract}

semi-dry cultivation reduced the yield up to $14 \%$ compare to the shallow water depth treatment. The alternate wetting and drying treatments have significantly improved the water productivity by $41.6 \%$, shallow water depth with wetting and drying increased by $24.2 \%$ relative to the shallow intermittent irrigation treatment, whereas the most saving water treatment i.e. the semidry cultivation performed quite similar with the shallow water depth treatment, as a result of low grain yields under the treatment.

Keywords: Pot Experiments; Water Management; Wetting and Drying

\section{INTRODUCTION}

Rice is important crop for billian people. In 2008, the rice consumption in Asia reached 400 million ton, around $90 \%$ of the world rice consumption [1]. For producing rice, a tremendous amount of water is used for the rice irrigation under the traditional irrigation technique called as a continuous deep flooding irrigation technique. In this technique, the paddy fields are inundated all the time starting from transplanting until nearly harvesting (e.g. [2]) at certain water depth that varies from $50 \mathrm{~mm}$ to 100 $\mathrm{mm}$. Almost $80 \%$ of water resources availability is used for irrigation purposes.

Currently, the traditional irrigation technique is getting difficult to be applied due to facing number of problems. The most obvious problem is decreasing trend in the water resources availability especially during dry season. On the other hand, the water demands for domestic and industrial water supply are increasing. As a result, the water availability for agriculture purposes is decreasing and conflicting among the water user and among farmers can not be avoided. Moreover, the tradi- 
tional irrigation technique has also been reported only yields a low of rice or low water productivity (e.g. [3]).

There is a major challenge for paddy rice cultivators to increase the water productivity. To grow rice with much less water is necessary and possible [4]. Research has been conducted to increase the water productivity for growing rice [2,3,5-9]. The formal research on water saving irrigation (WSI) treatments for paddy rice in China was started around 1985. The impetus came from different aspects such as shortages of food and electricity as well as water demand for industrial, domestic increased sharply. The research on improvement of water management for paddy rice was given priority for funding from the Government [2]. A number of WSI treatments have been studied. Among the available treatments include the system of rice intensification (SRI), alternate wetting and drying (AWD), shallow water depth with wetting and drying (SWD), and semi-dry cultivation (SDC) as the following.

\subsection{System of Rice Intensification}

System of rice intensification (SRI) is an innovative paddy cultivation method attaining high paddy yields with lower resource of input both water and fertilizer or cost saving. SRI was developed initially in the 1980s in Madagascar by Henri de Laulanie, a French Jesuit who spent more than three decades in Madagascar trying to devise better rice production method (e.g. [6]). The main feature of SRI regarding to water treatment is keeping the soil both moist and aerated so that roots have access to both water and oxygen. Great results of SRI practice have been reported in number of countries [6,10-12]. Uphoff and Randriamiharisoa [13] reported that double even triple yields over those of traditional rice culture were obtained by SRI in Madagascar. However, criticisms of these reports on SRI were made by some researchers such as [14-16] for the extraordinary yields, effectiveness of SRI practices and experimental procedures. Despite of the skeptics present of SRI, Horie et al. [17] explained that basic elements of SRI have proven potential to increase rice yield. Thus, if the elements of SRI are satisfied, SRI could be a high-yielding rice system.

\subsection{Shallow Water Depth with Wetting and Drying}

The feature of shallow water depth with wetting and drying (SWD) is comprehensive application of shallow water depth. Shallow water depth is equals to $10-40$ $\mathrm{mm}$ water depth on the surface of soil. The SWD has been spread widely in the southern provinces of China since 1980s. The standard water control adopted in the region is in the range of $60 \%$ SMC (saturated moisture content) to $40 \mathrm{~mm}$. However, the extra limit levels up to $70 \mathrm{~mm}$ are set up for storing more rainfall and drainage occurs when the water level goes beyond the limit (e.g. $[3,18])$.

\subsection{Alternate Wetting and Drying}

The alternate wetting and drying (AWD) irrigation technique by 2002 has been adopted on $40 \%$ of the rice growing areas in China. However many scientific issues remain to be addressed and the application of the AWD techniques in some regions is still very difficult because of both biophysical and socio-economic problems. Experience shows that demonstrations and training are needed to encourage farmer for applying the AWD [3]. The main feature of field water control under AWD is that paddy fields is intermittently submerged and dried. With the AWD treatment, there is no ponded water layer in paddy field for most of the season. It implies that fields are not kept continuously flooded but are allowed to dry intermittently beginning 30 days after transplanting of the crop. In the AWD the paddy field is submerged for 3 - 5 days with the water depth equal to about $30 \mathrm{~mm}$ and then allowed to dry naturally up to $70 \% \mathrm{SMC}$. Standard of field water control is between $70 \% \mathrm{SMC}$ as the lower limit and the upper limit is set up to $30 \mathrm{~mm}$ [3]. This practice allows paddy fields to reach a relatively dry condition prior to receipt of further water and store more water after rainfall. As a result, the utilization of rainfall is optimum and the irrigation water requirement reduced greatly. As this practice reduces irrigation water use so the water productivity is increased greatly. The AWD practice increases the water productivity on-farm level remarkable up to $1.52 \mathrm{~kg} / \mathrm{m}^{3}$ of water compare with the traditional one i.e. $1.04 \mathrm{~kg} / \mathrm{m}^{3}$ of water on average in the four provinces in China [3].

\subsection{Semi-Dry Cultivation}

There is a great difference of field water control between semi-dry cultivation (SDC) and SWD as well as AWD. For SDC, the water depth is maintained only in the revival of green to the middle stage of tillering, and there is no water depth on paddy field in the other stages in entire growing season. The standard of field water control is between 70\% SMC as lower limit and the upper limit is $0 \mathrm{~mm}$, except in the beginning stages up to $30 \mathrm{~mm}$. Comparing between SWD and AWD, SDC is the most high water efficiency. The water productivity could reach $70 \%$ higher than traditional continuous flooding technique [3]. 


\section{MATERIAL AND METHODS}

\subsection{Experimental Site}

The experiments were conducted at Kyushu University

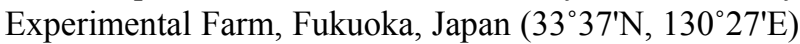
from mid August until beginning of November 2006 using pots with $15.6 \mathrm{~cm}$ diameter and $20 \mathrm{~cm}$ height. Each pot weight is measured using an available scale. Water was added to make a puddle soil. Scale was then used to measure the added water weight. The soil moisture suction of the soil was simply measured by using Daiki tensiometer (DIK-3162 pressure gauge type).

Rice variety used for the experiment was Nipponbare. The SRI method for transplanting was adopted i.e. young seedling of 9 days after seeding and single seedling for each pot was applied. Fertilizers used in the experiments consists of $0.24 \mathrm{~g} /$ pot of $\mathrm{N}, 0.24 \mathrm{~g} /$ pot of $\mathrm{P}$ and 0.24 $\mathrm{g} /$ pot of $\mathrm{K}$. One third of $\mathrm{N}$ and full doses of $\mathrm{P}$ and $\mathrm{K}$ fertilizers were applied at 7 days after transplanting (DAT). One third of $\mathrm{N}$ fertilizer was applied at growing stage (25 DAT) and the remaining of $\mathrm{N}$ fertilizer used as dressing was given at the panicle initiation stage i.e. at 40 DAT.

In the experiment, the number of tillers was counted for 10, 20, 30, 40, 50, 60 and 70 DAT. Based on the tillers, the effect of water irrigation treatments was analyzed by comparing with the tillers number resulted under shallow intermittent irrigation (SII) as a paddy control. The SII is chosen due to less water needed compare to continuous flooding (traditional method). An example of SII that has getting much attention is SRI practice. The maximum productive tillers among the treatments are the most potential treatment to yield the highest spikelets or grain results, whereas water irrigation used and the resulted grain affect to the water productivity.

\subsection{Water Saving Irrigation Treatments}

Eight water irrigation treatments were tested in the study. Each treatment consists of three pot replicates. The amount of irrigated water and when it should be irrigated vary among the treatments and depend on evapotranspiration rate, soil moisture condition and the water irrigation treatment used. For this purpose, daily measurement of the pot weight was carried out. The main features of the water irrigation treatments are described as the following.

\subsubsection{Shallow Intermittent Irrigation (SII)}

In this treatment, shallow intermittent irrigation (SII) [19] was applied where the maximum water depth was set up at $20 \mathrm{~mm}$ and then it dries naturally. The irrigated water was added when the depth reaches $0 \mathrm{~mm}$ (satu- rated condition) or up to small cracks emerging (soil moisture suction up to $-10 \mathrm{kPa}$ ). This kind of water treatment was applied for entire growing period from transplanting up to ripening. An example of SII that is normally applied in paddy rice cultivation is the SRI.

\subsubsection{Alternate Wetting and Drying (AWD)}

The feature of water management for AWD is that paddy pot is intermittently submerged and drying. The maximum water depth was set up to the maximum level at $20 \mathrm{~mm}$ and the minimum is $70 \%$ SMC (saturated moisture content) or when the soil moisture suction reaches $-70 \mathrm{kPa}$. In this study, four different AWDs were designed based on the starting point of no water depth i.e.: AWD-1, alternate wetting and drying begin at 20 DAT; AWD-2, alternate wetting and drying begin at 30 DAT; AWD-3, alternate wetting and drying begin at 40 DAT, and AWD-4, alternate wetting and drying begin at 50 DAT.

\subsubsection{Combining Shallow Water Depth with Wetting and Drying (SWD)}

In the SWD the maximum water depth was set up to $20 \mathrm{~mm}$ while the minimum was at $70 \%$ SMC. In this study two types of SWD were used i.e. SWD-1 for water management where the drying begins at the middle stage of tillering (in this study at 20 DAT) and SWD-2 when the drying begins at the late stage of tillering (40 DAT). Shallow water depth (maximum is $20 \mathrm{~mm}$ and minimum is $0 \mathrm{~mm}$ water depth) were applied up to tillering, during elongating and flowering stage, whereas wetting and drying treatments were applied continuously from milk ripening until ripening.

\subsubsection{Semi-Dry of Cultivation (SDC)}

There is a great difference of water irrigation treatment between the SDC and the above mentioned. For the SDC, shallow water depth is only maintained up to tillering stage. The maximum water depth is $20 \mathrm{~mm}$. There is no water depth in the other stages in entire growing season. In these stages, the maximum water depth is $0 \mathrm{~mm}$ and the minimum is $70 \mathrm{SMC}$. The SDC water irrigation treatment was started where no water depth begins at the middle (20 DAT) stage of tillering.

\section{RESULTS AND DISCUSSION}

\subsection{Agronomic Parameters}

Average tillers number under different water management treatments are given at Figure 1. The figure clearly shown that up to 40 DAT there is no significant difference among the treatments, however, starting at 45 DAT, the SII method gives more tillers than others. Un- 
der the AWDs, however, the number spikelets are slightly better than others. The differences are not significantly different at 0.05 probability level according to Duncan's multiple comparison test (Table 1). Better performance of the AWDs is probably due to the combined effect of alternating and drying processes that creating aeration soil more frequently than other treatments and young transplanted seedling. Wetting and drying improves the root system environment, so that the root system has enough oxygen and water during tiller development.

According to Horie et al. [17], transplanting young seedling has advantages than aged ones (traditional method). The advantages lie in higher tolerance to transplanting stresses in younger seedling than aged ones. However, not all these tillers develop to maturity (productive tillers), some degenerate to become dormant when young and some die later, depending on environmental and nutritional conditions [17] as shown in Table $\mathbf{1}$.

\subsection{Water Parameters}

Water management embraces the control of water for optimum rice yield and the best use of a limited supply of water. Water required to produce optimum yield i.e. irrigated water must satisfy the evapotranspiration needs of the paddy rice and losses through percolation and seepage. In this study, irrigated water is the amount of water given during paddy rice cultivation started from transplanting up to ripening stage excluding water needed for land preparation. The irrigated water is purely for rice growing since there is no either seepage or percolation from the pot experiments. The irrigated water requirement varies depending on water irrigation treatments as presented in Table 2. Amount of irrigated water and water saving compared to paddy control (SII) are also given in Table 2.

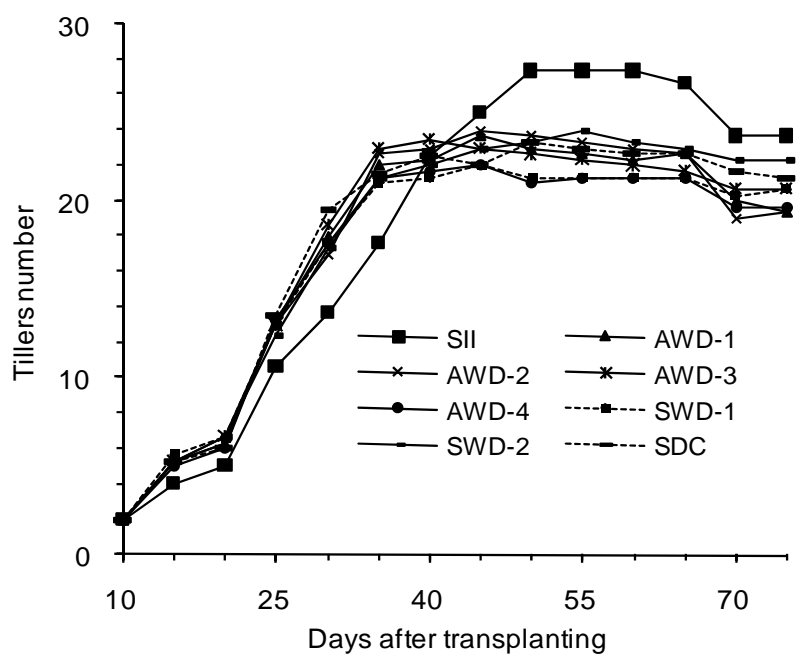

Figure 1. Effect of water treatments on tillers number during vegetative growth.

Table 1. Water saving for different water saving irrigation treatments.

\begin{tabular}{cccc}
\hline \multirow{2}{*}{ WSI treatment } & $\begin{array}{c}\text { Irrigated water } \\
(\mathrm{mm})\end{array}$ & $\mathrm{mm}$ Water saving relative to control \\
\cline { 3 - 4 } & 861 & 0 & 0 \\
\hline SII (control) & 711 & 150 & 17.4 \\
AWD-1 & 736 & 124 & 14.4 \\
AWD-2 & 781 & 79 & 9.2 \\
AWD-3 & 762 & 98 & 11.4 \\
AWD-4 & 783 & 78 & 9.1 \\
SWD-1 & 846 & 14 & 1.7 \\
SWD-2 & 703 & 158 & 18.4 \\
SDC
\end{tabular}

Table 2. Number of tillers and spikelets under different water irrigation treatments.

\begin{tabular}{ccccc}
\hline \multirow{2}{*}{ Water treatment } & \multicolumn{2}{c}{ Number of tillers } & \multicolumn{2}{c}{ Spikelets } \\
\cline { 2 - 5 } & 45 DAT & Productive & Total & Per panicle \\
\hline SII (control) & $25.0^{\mathrm{a}}$ & $16.7^{\mathrm{ab}}$ & $1204^{\mathrm{ab}}$ & $72.3^{\mathrm{ab}}$ \\
AWD-1 & $23.7^{\mathrm{ab}}$ & $16.0^{\mathrm{b}}$ & $1098^{\mathrm{b}}$ & $68.7^{\mathrm{bc}}$ \\
AWD-2 & $24.0^{\mathrm{ab}}$ & $16.7^{\mathrm{ab}}$ & $1182^{\mathrm{ab}}$ & $71.0^{\mathrm{ac}}$ \\
AWD-3 & $23.0^{\mathrm{ab}}$ & $16.3^{\mathrm{ab}}$ & $75.1^{\mathrm{a}}$ & $75.6^{\mathrm{a}}$ \\
AWD-4 & $22.0^{\mathrm{b}}$ & $17.3^{\mathrm{ab}}$ & $1303^{\mathrm{a}}$ & $65.9^{\mathrm{c}}$ \\
SWD-1 & $22.0^{\mathrm{b}}$ & $17.7^{\mathrm{ab}}$ & $1163^{\mathrm{ab}}$ & $70.2^{\mathrm{ac}}$ \\
SWD-2 & $23.0^{\mathrm{ab}}$ & $19.0^{\mathrm{a}}$ & $1199^{\mathrm{ab}}$ & $66.1^{\mathrm{ab}}$ \\
SDC & $22.7^{\mathrm{ab}}$ & $18.0^{\mathrm{ab}}$ & & \\
\hline
\end{tabular}

Note: In a column, means followed by a different letter are significantly different at the 0.05 probability level according to Duncan's multiple comparison test. 
The table shows clearly that AWD, SWD and SDC treatments reduce the amount of water needed for paddy rice cultivation compared to the SII as a control treatment. The irrigated water reduction varies from $1.7 \%$ to $17.4 \%$. In terms of irrigated water, the SDC is the most promising method for water saving treatment, since under SDC there is no standing water in the paddy field and most of the time the soil is below saturated condition. In addition for reducing irrigated water, the irrigation treatment under SDC offers longer irrigation time interval. That is more appropriate in practice compared with the SII (for instance SRI), since to maintain the soil under saturated condition as in the SII treatment is not an easy task in real paddy fields. Longer irrigation interval is important factor for irrigation water management especially for large area, rotation irrigation delivery system due to limited water.

\subsection{Water Productivity}

The water productivity is defined as the amount of filled spikelets or grain produced per unit quantity of water. The water productivity is obtained by dividing the total grain produced in each pot ( $\mathrm{g}$ grain) by the total amount of water used $\left(\mathrm{kg}^{-1}\right.$ water). As total irrigated water used and the yield vary among water irrigation treatments, their water productivity will have different values as shown in Table 3.

Table 3 shows that the AWDs produced more grain yield than other treatments. The increasing grain yield relative to the SII could reach $42 \%$ under AWD-4. On average the AWD and SWD increased the grain yield by $22.9 \%$ and $17.9 \%$, whereas the SDC reduced the yield up to $14 \%$ compare to the SII treatment.

Due to reducing supply of water using intermittent irrigation especially in AWDs (Table 2) and relatively higher grain yield compare with other treatments (Table 3), the water productivity under AWDs treatments were higher than others. Irrespective to irrigated water and consumptive water use, the water productivity with AWD-1, AWD-2 and AWD-4 increase by 44.8\%, 39.6\% and $60.2 \%$ compared to SII treatments, respectively. On average AWDs treatments have significantly improved the water productivity by $41.6 \%$, SWDs increase by $24.2 \%$ relative to the SII treatments. On the other hand, the SDC performs quite similar with the SII treatments, since the grain yields under SDC treatment was less than the SII.

Table 3 shows that all the treatments give very low water productivity compare to other study results. For instance, Chapagain and Yamaji [9] based on experimental research conducted in Japan reported that combinations of practices in the intermittent irrigation plots yield $1.74 \mathrm{~g}$ grain $/ \mathrm{kg}$ water with SRI management and AWD as compared to $1.23 \mathrm{~g}$ grain $/ \mathrm{kg}$ water from normal planting methods with ordinary water management. The low yield caused by cold damage is probably occurred in the experiment. The damage affects to the rice growing especially during flowering and grain filling stages, since in the experiment the flowering started at the mid of October that is to late for paddy rice cultivation in Japan. As a result, the unfilled spikelet became very high for all the treatments, it reached $60 \%$ to $75 \%$ of the total spikelet that is very high compare to the normal condition i.e. less than $20 \%$.

\subsection{Selection of the Most Appropriate Water Saving Irrigation Treatments}

The most appropriate water saving irrigation treatment of rice cultivation will depend on a number of factors including natural resources condition (soil, topography, climate) and socio-culture (farmer condition). Number of criteria could be used for selecting the most approprite water saving irigation treatment including grain yield, amount of irrigated water needed, water availability and accesbility, water productivity and practicality.

Table 3. Yield and water productivity for different water irrigation treatments.

\begin{tabular}{|c|c|c|c|c|c|}
\hline \multirow{2}{*}{ Treatment } & \multicolumn{2}{|c|}{ Yield } & \multirow{2}{*}{$\begin{array}{l}\text { Water } \\
(\mathrm{g})\end{array}$} & \multicolumn{2}{|c|}{ Water productivity } \\
\hline & (g/pot) & $\%$ difference & & (g grain/kg water) & $\%$ difference \\
\hline SII (control) & 8.41 & 0.0 & 16879 & 0.50 & 0.0 \\
\hline AWD-1 & 10.05 & 19.5 & 13940 & 0.72 & 44.8 \\
\hline AWD-2 & 10.04 & 19.4 & 14445 & 0.70 & 39.6 \\
\hline AWD-3 & 9.30 & 10.7 & 15324 & 0.61 & 21.9 \\
\hline AWD-4 & 11.93 & 41.9 & 14950 & 0.80 & 60.2 \\
\hline SWD-1 & 8.88 & 5.6 & 15352 & 0.58 & 16.1 \\
\hline SWD-2 & 10.94 & 30.2 & 16597 & 0.66 & 32.4 \\
\hline SDC & 7.21 & -14.2 & 13781 & 0.52 & 5.0 \\
\hline
\end{tabular}


Grain yield is not the only factor that attract the farmers to apply the current the sugested method. Even though the SII management practices yields much higher grain than the traditional (continuous flooding) as reported by many researchers $[6,12,20]$, it takes time for farmers to apply the SRI management practice that mainly consist of using young seedling, one seddling per hill, soil moist condition, wider spacing. Even at the some places, the farmers do not want to try it due to they think it is labour intensive (e.g. [21,22]), difficult to maintain especially weeding the weed that grow fastly due to there is no ponding water and keeping the soil at moist condition rather than flooded (e.g. [22]).

In terms of maintaining the water in the paddy field, it is likely that the AWD could be accepted by the farmers not only due to yield higher grain and water productivity that others water saving irrigation (see Table 3) but also more reliable in practice. The irrigation water interval is much longer than SRI current practice, it is appropriate for paddy field that used rotation irrigation system due to limited water supply and the AWD is easier for farmers to use than aerobic rice systems like the SDC (e.g. [23]). The use of combination between the SRI management practice and AWD for paddy rice cultivation is also supported by others [9,20,22]. Uphoff [20] mentioned that the SRI water management practices currently recommended may still be suboptimal for many conditions, with more water reduction possible. Based on the experiment combining between the SRI current management practice with AWD increased water productivity significantly than the normal method (e.g. [9,22]).

\section{CONCLUSIONS}

The experiment revealed that the amount of irrigated water for paddy rice cultivation, grain yield and water productivity are highly depends on the water irrigation treatment used. A combination between the SII current management practice and other water irrigation treatments could increase the water productivity by reducing the water irrigated used and increasing the grain yield. Among the water irrigation treatment tested together with the SII management practice, the AWD is the most promising one followed by SWD, the SII current management practice and the SDC due to the following:

1) The AWD could reduce the irrigated water up to $13.1 \%$ compared with the SII method, whereas the SWD and SDC reduced the water up to 5.4 and 18.4 , respectively.

2) On average the AWDs and SWDs increased the grain yield by $22.9 \%$ and $17.9 \%$, whereas the SDC reduced the yield up to $14 \%$ compare to the SII treatment.

3) The AWDs treatments have significantly improved the water productivity by $41.6 \%$, the SWDs increase by $24.2 \%$ relative to the SII treatments. On the other hand, the SDC performs quite similar with the SII treatments, since the grain yields under SDC treatment was less than the SII.

\section{ACKNOWLEDGEMENTS}

The authors thank to the Hitachi Schollarship Foundation for the financial support to conduct the experiment in Kyushu University Fukuoka Japan. The experiment was conducted at the Kyushu University Experimental farm.

\section{REFERENCES}

[1] IRRI (2009) Consumption and calorie supply: Rough rice consumption, by country and geographical regionUSDA.

http://beta.irri.org/solutions/index.php?option=com cont ent\&task= view\&id=250.

[2] Li, Y. and Barker, R. (2004) Increasing water productivity for paddy irrigation in China. Paddy and Water Environmental, 2, 187-193.

[3] Zhi, M., (2002) Water efficient irrigation and environmentally sustainable irrigated rice production in China. http://www.icid.org/wat_mao.pdf

[4] Rijsberman, F. (2004) Growing more rice with less water. Paddy and Water Environmental, 2, 181-183.

doi:10.1007/s10333-004-0059-y

[5] Barker, R., Tuong, T.P., Li., Y., Castillo, E.G. and Bouman, B.A.M. (2004) Growing more rice with less water: Research findings from a study in China. Paddy and Water Environmental, 2, 185.

doi:10.1007/s10333-004-0067-y

[6] Satyanarayana, A., Thiyagarajan, T.M. and Uphoff, N. (2007) Opportunities for water saving with higher yield from the system of rice intensification. Irrigation Science, 25, 99-115. doi:10.1007/s00271-006-0038-8

[7] Sujono, J., Nurrochmad, F. and Jayadi, R. (2006) Growing more paddy with less water. Research Report, Department Civil and Environmental Engineering, Faculty of Engineering, Gadjah Mada University, Yogyakarta.

[8] Sujono, J. (2007) Water saving irrigation on paddy fields for increasing productivity and for flood reduction, IASTED International Conference on Water Resources Management (WRM 2007) 20 August 2007, Honolulu.

[9] Chapagain, T. and Yamaji, E. (2009) The effects of irrigation method, age of seedling and spacing on crop performance, productivity and water-wise rice production in Japan. Paddy and Water Environmental, 8, 81-90. doi:10.1007/s10333-009-0187-5v

[10] Namara R.E., Weligamage, P. and Barker, R. (2003) Prospects for adopting system of rice intensification in Sri Lanka: A socio-economics assessment. Research Report 75, International Water Management Institute, Colombo.

[11] Nippon Koei (2005) The system of rice intensification in East Indonesia. Nippon Koei Co., Ltd., Tokyo.

[12] Sato S. (2006) An evaluation of the system of rice intensification (SRI) in Eastern Indonesia for its potential to 
save water while increasing productivity and profitability. International Dialogue on Rice and Water: Exploring Options for Food Security and Sustainable Environments, IRRI, Los Banos, 7-8 March 2006.

[13] Uphoff, N. and Randriamiharisoa, R. (2002) Reducing water use in irrigated rice production with the Madagascar System of Rice Intensification. In: Bouman, B.A.M., et al., Eds., Water-Wise Rice Production: Proceeding of the International Workshop on Water-Wise Rice Production, International Rice Research Institute, Los Banos, 8-11 April 2002.

[14] Sheehy, J.E., Peng, S., Dobermann, A., Mitchell, P.L., Ferrer, A., Yang, J., Zou, Y., Zhong, X. and Huang, J. (2004) Fantastic yields in the system of rice intensification: Fact or fallacy? Field Crops Research, 88, 1-8. doi:10.1016/j.fcr.2003.12.006

[15] Dobermann, A. (2004) A critical assessment of the system of rice intensification (SRI). Agricultural Systems, 79, 261-281. doi:10.1016/S0308-521X(03)00087-8

[16] Sinclair, T.R. and Cassman, K.G. (2004) Agronomic UFOs? Field Crops Research, 88, 9-10. doi:10.1016/j.fcr.2004.01.001

[17] Horie, T., Shiraiwa, T., Homma, K., Katsura, K., Maeda, S. and Yoshida, H., (2005) Can yields of lowland rice resume the increases that they showed in the 1980s? Plant Production Science, 8, 259-274. doi:10.1626/pps.8.259

[18] Lin, X., Zhou W., Zhu D. and Zhang, Y. (2005) Effect of
SWD irrigation on photosyntesis and grain yield of rice (Oryza sativa L.). Field Crops Research, 94, 67-75. doi:10.1016/j.fcr.2004.11.007

[19] Won, J.G., Choi, J.S., Lee, S.P., Son, S.H. and Chung, S.O. (2005) Water saving by shallow intermittent irrigation and growth. Plant Production Science, 8, 487-492. doi: $10.1626 /$ pps.8.487

[20] Uphoff, N. (2006) The system of rice intensification (SRI) as a methodology for reducing water requirements in irrigated rice production. International Dialogue on Rice and Water: Exploring Options for Food Security and Sustainable Environments, IRRI, Los Baños, 7-8 March 2006.

[21] Moser, C.M. and Barrett, C.B. (2003) The disappointing adoption dynamics of a yield-increasing, low externalinput technology: The case of SRI in Madagascar. Agricultural Systems, 76, 1085-1100. doi:10.1016/S0308-521X(02)00041-0

[22] Senthilkumar, K., Bindraban, P.S., Thiyagarajan, T.M., De Ridder, N., Giller, K.E. (2008) Modified rice cultivation in Tamil Nadu, India: Yield gains and farmers. Agricultural Systems, 98, 82-94. doi:10.1016/j.agsy.2008.04.002

[23] Matsuo, N. and Mochizuki, T., (2009) Growth and yield of six rice cultivars under three water-saving cultivations. Plant Production Science, 12, 514-525. doi:10.1626/pps.12.514 